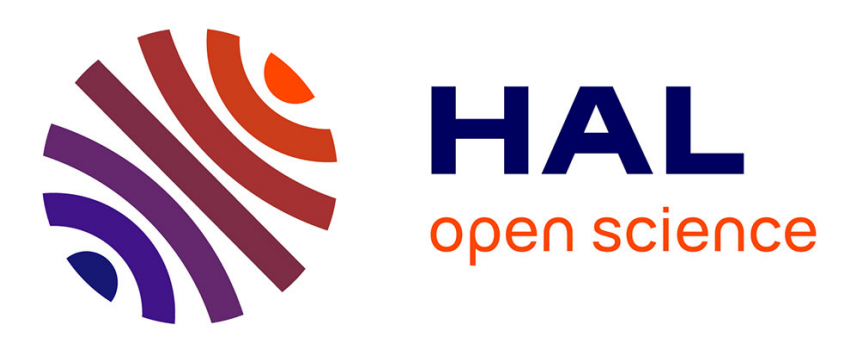

\title{
Natural convection heat transfer coefficients in Phase Change Material (PCM) modules with external vertical fins
}

Albert Castell, Cristian Solé, Marc Medrano, Joan Roca, Luisa F. Cabeza, Daniel García

\section{To cite this version:}

Albert Castell, Cristian Solé, Marc Medrano, Joan Roca, Luisa F. Cabeza, et al.. Natural convection heat transfer coefficients in Phase Change Material (PCM) modules with external vertical fins. Applied Thermal Engineering, 2008, 28 (13), pp.1676. 10.1016/j.applthermaleng.2007.11.004 . hal-00498965

\section{HAL Id: hal-00498965 https://hal.science/hal-00498965}

Submitted on 9 Jul 2010

HAL is a multi-disciplinary open access archive for the deposit and dissemination of scientific research documents, whether they are published or not. The documents may come from teaching and research institutions in France or abroad, or from public or private research centers.
L'archive ouverte pluridisciplinaire HAL, est destinée au dépôt et à la diffusion de documents scientifiques de niveau recherche, publiés ou non, émanant des établissements d'enseignement et de recherche français ou étrangers, des laboratoires publics ou privés. 


\section{Accepted Manuscript}

Natural convection heat transfer coefficients in Phase Change Material (PCM) modules with external vertical fins

Albert Castell, Cristian Solé, Marc Medrano, Joan Roca, Luisa F. Cabeza, Daniel García

PII:

S1359-4311(07)00371-7

DOI:

10.1016/j.applthermaleng.2007.11.004

Reference:

ATE 2304

\section{APPLIED}

THERMAL

ENGINEERING

To appear in:

Applied Thermal Engineering

Received Date:

9 May 2006

Revised Date:

28 August 2007

Accepted Date:

4 November 2007

Please cite this article as: A. Castell, C. Solé, M. Medrano, J. Roca, L.F. Cabeza, D. García, Natural convection heat transfer coefficients in Phase Change Material (PCM) modules with external vertical fins, Applied Thermal Engineering (2007), doi: 10.1016/j.applthermaleng.2007.11.004

This is a PDF file of an unedited manuscript that has been accepted for publication. As a service to our customers we are providing this early version of the manuscript. The manuscript will undergo copyediting, typesetting, and review of the resulting proof before it is published in its final form. Please note that during the production process errors may be discovered which could affect the content, and all legal disclaimers that apply to the journal pertain. 


\section{Natural convection heat transfer coefficients in Phase Change Material (PCM) modules with external vertical fins}

Albert Castell, Cristian Solé, Marc Medrano, Joan Roca, Luisa F. Cabeza ${ }^{1}$

Dept. d'Informàtica i Eng. Industrial, Universitat de Lleida

Pere de Cabrera s/n, 25001 Lleida, Spain

Tel.+34 973003576, Fax.+34 973003575, e-mail: Icabeza@diei.udl.es

\section{Daniel García}

Dept. Projectes d'Enginyeria, Universitat Politècnica de Catalunya

Colom 11, 08222 Terrassa, Spain

\section{Abstract}

To determine the heat transfer coefficient by natural convection for specific geometries, experimental correlations are used. No correlations were found in the literature for the geometries studied in this work. These geometries consisted of a cylindrical module of $88 \mathrm{~mm}$ of diameter and $315 \mathrm{~mm}$ height with external vertical fins of $310 \mathrm{~mm}$ height and 20 and $40 \mathrm{~mm}$ length. To determine the heat transfer coefficient by natural convection, experimental work was done. This module, containing PCM (sodium acetate trihydrate), was situated in the middle upper part of a cylindrical water tank of $440 \mathrm{~mm}$ of diameter and $450 \mathrm{~mm}$ height. The calculated heat transfer coefficient changed by using external fins, as the heat transfer surface was increased. The temperature variation of the PCM and the water are presented as a function of time, and the heat transfer coefficient for different fins is presented as a function of the temperature difference. Experimental correlations were obtained, presenting the Nusselt number as a function of different dimensionless numbers. Different correlations were analysed to find which one fit better to the experimental data.

\footnotetext{
${ }^{1}$ Corresponding author
} 
KEYWORDS: Nusselt number, Rayleigh number, experimental correlation, heat transfer enhancement, Phase Change Material (PCM)

\section{Introduction}

Thermal energy storage systems are an important requirement for many applications due to the non-coincidence of heat demand and supply or availability. One of the typical examples of such mismatch is solar energy. Among the thermal energy storage concepts, latent heat thermal storage using PCM's is regarded as a promising technology. Their use in domestic hot water (DHW) tanks would keep hot water for a longer time. In such a system, a lot of energy can be stored as latent heat, but it should be able to be transferred from the PCM to the water when needed, therefore heat transfer within the PCM and to the water is of high interest $[1,2]$.

There are several methods to enhance the heat transfer in a latent heat thermal store. The use of fins inside the PCM has been extendedly studied. These fins can be axial or radial and are usually attached to the tubes. In this case the most important part is the formulation of phase change problems. Several theoretical techniques have been developed, such as the enthalpy method by Ismail $[3,4,5]$, the Landau transform method associated with the finite volumes method, the interface immobilization method together with the finite volumes approach, or the integral energy method (Ismail [5]). Ismail [3, 4] presented a comprehensive review of literature on the subject as well as the results of many experimental and numerical studies on phase change heat transfer into and around simple and complex geometries.

Mehling et al., [6, 7, 8] and Py et al. [9] proposed a graphite-compound-material, where the PCM is embedded inside a graphite matrix. When using these PCM-graphite composites inside metal modules, the heat barrier is the heat transfer from the metal container to the water [8]. By using fins the heat transfer area is extended and the coefficient of heat transfer by natural convection changes, improving heat transfer form the container to the water. 
Fins geometry is an important parameter when considering the addition of fins in a PCM module. In a vertical module two different fins geometries can be considered: horizontal and vertical fins. There is much more literature for horizontal fins [10-22], but this geometry interferes with the natural convection in the PCM module. On the other hand there is no literature for vertical fins around circular vertical tubes, but this geometry would improve natural convection in the water side of the PCM module. Because of this, in this work external vertical fins were used to increase the heat transfer from the PCM to the water.

There were no literature references for vertical and cylindrical modules with external and vertical fins. Heat transfer coefficient for natural convection is typically determined using experimental correlations. Lots of specific geometries have been studied and correlations are available in the literature $[23,24]$. In this work an experimental set-up was used to evaluate the natural convection heat transfer coefficient for two specific geometries. Correlations of Nusselt number as a function of Rayleigh and effective Rayleigh number were obtained.

\section{Experimental work}

\section{a) Experiments done}

To determine the effect of adding vertical fins to the external part of the module, some experiments were conducted. The PCM-graphite composite used was sodium acetate trihydrate with graphite (90:10 vol.\%). This product has a melting point of $58^{\circ} \mathrm{C}$, melting enthalpy between 180 and $200 \mathrm{~kJ} / \mathrm{kg}$, density between 1.350 and $1.400 \mathrm{~kg} / \mathrm{m}^{3}$, heat capacity of $2,5 \mathrm{~kJ} / \mathrm{kg} \cdot \mathrm{K}$, and thermal conductivity between 2 and $5 \mathrm{~W} / \mathrm{m} \cdot \mathrm{K}$.

Three different modules were used: one without fins, another one with small fins ( $20 \mathrm{~mm}$ length) and the last one with big fins ( $40 \mathrm{~mm}$ length). Each module had 8 external and vertical fins of 2 $\mathrm{mm}$ of thickness, providing a $28,45 \%$ and $44,28 \%$ increase of the heat transfer surface, respectively, compared to the reference module without fins. Fig. 1 shows the considered 
configuration. The PCM module was $88 \mathrm{~mm}$ of diameter and $310 \mathrm{~mm}$ of height with a thickness of $2 \mathrm{~mm}$.

The experimental work reproduced the behaviour of the PCM modules in a DHW tank. The dimensions of the tank used were: $440 \mathrm{~mm}$ of diameter and $450 \mathrm{~mm}$ of height. The tank was insulated using an elastomeric insulating material of $10 \mathrm{~mm}$ of thickness. Five $\mathrm{K}$ type thermocouples and a data-logger (STEP DL01-CPU) instrumented the experimental set-up. Two thermocouples were located inside the PCM module (one in the centre and the other at half distance between the first one and the metal container). The other ones were situated inside the water, outside the PCM module, one of them in contact with the external surface of it. The distance between the inside water thermocouples was $50 \mathrm{~mm}$, and all thermocouples were at $135 \mathrm{~mm}$ distance from the top of the tank. Fig. 2 and Fig. 3 illustrate the instrumentation of the experiments.

The experimental work consisted of introducing the module containing melted PCM at $70^{\circ} \mathrm{C}$ into the cold water tank to evaluate the heat transfer phenomenon. The experiment was stopped when PCM and water temperatures were the same.

\section{b) Natural convection heat transfer coefficient}

Once the experimental work was done, the heat transfer coefficient by natural convection for this specific geometry could be calculated. To determine this coefficient a one-dimensional study was done in order to simplify the calculations. A three-dimensional behavior could be expected because of the stratification of the water, but since the experiments were very short it would be negligible. In future works, the stratification in the water tank when using encapsulated PCM inside (considering different distributions and geometries) will be studied.

The procedure used to determine the heat transfer coefficient by natural convection was the following: 
1. Calculation of the heat transfer rate.

The PCM (sodium acetate trihydrate) was mixed with graphite in a composite.

Therefore, during all the experimental processes the mixture was not melted inside the PCM module, remaining in solid phase; only the sodium acetate trihydrate went through the melting/solidifying process, but not affecting the solid structure of the composite. Therefore, the heat transfer rate inside the PCM module could be determined using conduction equations (Fourier law). In this work, the transient effect was considered discretizing the data over time, therefore, the heat flux could be calculated using the following equation:

$$
q=k_{P C M} \cdot A_{\text {cond }} \cdot\left(T_{P C M, 1 / 2}-T_{\text {surface }}\right)
$$

where:

$$
A_{\text {cond }}=\frac{2 \cdot \pi \cdot L_{P C M}}{\operatorname{Ln}\left[\frac{r_{P C M}}{0.003}\right]}
$$

Note that in the equations above the thermal conductivity of the material is considered constant with time and temperature. Although this assumption might give an error to the calculation, especially during phase change, when the PCM is mixed with graphite the driving force in the conduction is the graphite, therefore the error is low enough.

2. Calculation of the natural convection heat transfer coefficient.

Once the heat transfer rate was calculated, the natural convection heat transfer coefficient could be determined using Newton law.

$$
h_{P C M}=\frac{q}{A_{\text {transfer }} \cdot\left(T_{\text {surface }}-T_{\text {close }}\right)}
$$

where:

$$
A_{\text {transfer }}=2 \cdot \pi \cdot r_{P C M} \cdot L_{P C M}
$$

for the module without fins, and 


$$
A_{\text {tranfer }}=2 \cdot \pi \cdot r_{P C M} \cdot L_{P C M}+2 \cdot N_{f i n} \cdot W_{f i n} \cdot L_{P C M}
$$

for the modules with vertical fins.

\section{c) Natural convection heat transfer coefficient correlations}

From the experimental data, experimental correlations were determined for each specific geometry. These equations provided the heat transfer coefficient for natural convection as a function of the temperature difference of the system. The defining dimensionless numbers of the problem, considering its geometry and boundary conditions, were:

$$
\begin{aligned}
& \frac{D_{P C M}}{L_{P C M}}=0,284 ; \frac{s}{L_{P C M}}=0,11 ; \frac{D_{t}}{L_{P C M}}=1,397 ; \frac{L_{t}}{L_{P C M}}=1,429 ; \quad X=\frac{x}{L_{P C M}} ; \quad Y=\frac{y}{L_{P C M}} \\
& \Phi=\frac{T-T_{\text {close }}}{T_{\text {surface }}-T_{\text {close }}} \\
& G r=\frac{g \cdot \beta \cdot\left(T_{\text {surface }}-T_{\text {close }}\right) \cdot L_{P C M}{ }^{3}}{v^{2}} ; \operatorname{Pr}=\frac{\mu \cdot C_{p}}{h}
\end{aligned}
$$

and,

$$
\begin{aligned}
& \frac{W_{f i n}}{L_{P C M}}=0,063 ; \text { for } 20 \mathrm{~mm} \text { fins } \\
& \frac{W_{f i n}}{L_{P C M}}=0,127 ; \text { for } 40 \mathrm{~mm} \text { fins }
\end{aligned}
$$

\section{d) Rayleigh correlations}

Different correlations for Nusselt number were studied and compared with each other to achieve the best fit with the experimental results. Three dimensionless numbers (Rayleigh, Prandtl, Grashof) and several combinations of them were used. 
The most significant and used dimensionless numbers in natural convection systems and their combination were studied. The fluid properties are a function of the temperature and were evaluated at the registered temperature. The following equations were used to calculate them:

$$
\begin{aligned}
& G r=\frac{g \cdot \beta \cdot\left(T_{\text {surface }}-T_{\text {close }}\right) \cdot L_{P C M}{ }^{3}}{v^{2}} \\
& \beta=\frac{1}{T_{f}} \\
& T_{f}=\frac{T_{\text {surface }}+T_{\text {close }}}{2} \\
& \operatorname{Pr}_{H_{2} O}=\frac{\mu_{H_{2} O} \cdot C_{p}}{k_{H_{2} O}} \\
& R a=G r \cdot \operatorname{Pr} \\
& R a_{e f f}=G r \cdot \operatorname{Pr} \cdot \frac{W_{f i n}}{L_{P C M}}
\end{aligned}
$$

In equation $3 f$, Rayleigh number is modified by a ratio of fin width by fin height. These modifications introduced in the dimensionless number a measure of using different fins.

\section{Results}

The experimental results showed an increase in the heat transfer rate when using PCM modules with vertical fins. This effect can be measured by the time needed by the modules to heat the water. Fig. 4a shows the time needed to heat the water due to the PCM phase change. To cool down the PCM from $60^{\circ} \mathrm{C}$ to $45^{\circ} \mathrm{C}$ (including the solidification of the material) using a PCM module without fins the time needed was about 17 minutes. 
When using $20 \mathrm{~mm}$ fins, to achieve the same temperature decrease as in the experiments without fins, the time necessary was about 13 minutes (a reduction of $23,53 \%$ ). Fig. $4 b$ shows the heating, and melting and cooling down processes of the water and the PCM, respectively. Finally, PCM modules with $40 \mathrm{~mm}$ fins reduced the cooling down time to 7 minutes for the same temperature decrease (a reduction of $58,82 \%$ ). Fig. $4 \mathrm{c}$ shows the heating and cooling down process for these experiments.

To determine the heat transfer coefficient a one-dimensional study was done. The stratification of the water was neglected in this work. In future works, the stratification of the water tank when using PCM inside will be studied.

The heat transfer coefficient for natural convection for each PCM module geometry is compared in Fig. 5 as a function of temperature difference $\Delta T=T_{\text {surface }}-T_{\text {close }}$. When using $20 \mathrm{~mm}$ fins, the temperature difference $\Delta \mathrm{T}$ necessary to achieve the maximum heat transfer coefficient $(\mathrm{h}=179$ $\mathrm{W} / \mathrm{m}^{2} \mathrm{~K}$ with no fins; $\mathrm{h}=177 \mathrm{~W} / \mathrm{m}^{2} \mathrm{~K}$ with $20 \mathrm{~mm}$ fins) experienced a threefold decrease $(\Delta \mathrm{T}=3,5$ ${ }^{\circ} \mathrm{C}$ with no fins; $\Delta \mathrm{T}=1,1^{\circ} \mathrm{C}$ with $20 \mathrm{~mm}$ fins). On the other hand, using $40 \mathrm{~mm}$ fins the temperature difference had a fourfold decrease $\left(\Delta \mathrm{T}=0,8^{\circ} \mathrm{C}\right)$, but the maximum heat transfer coefficient decreased too $\left(h=159 \mathrm{~W} / \mathrm{m}^{2} \mathrm{~K}\right)$.

Fig. $6 \mathrm{a}$ and Fig. $6 \mathrm{~b}$ represent the natural convection heat transfer coefficient as a function of the temperature difference $\Delta \mathrm{T}$, for $20 \mathrm{~mm}$ and $40 \mathrm{~mm}$ fins, respectively. The experimental correlations were divided in three parts to achieve the best fit with the experimental data. The valid range of temperature differences was from 0.7 to $9.2^{\circ} \mathrm{C}$ for $20 \mathrm{~mm}$ fins geometry, and from 0.2 to $13.7^{\circ} \mathrm{C}$ for $40 \mathrm{~mm}$ fins.

For $20 \mathrm{~mm}$ fins, the experimental correlation is:

$$
\begin{cases}h_{P C M}=-490.6 \cdot \Delta T^{2}+1249 \cdot \Delta T+619 & 0.7 \leq \Delta T \leq 1.3 \\ h_{P C M}=-35.7 \cdot \Delta T+226 & 1.3<\Delta T \leq 3.7 \\ h_{P C M}=1.35 \cdot \Delta T^{2}-24 \cdot \Delta T+163.7 & 3.7 \leq \Delta T \leq 9.2\end{cases}
$$


For $40 \mathrm{~mm}$ fins, the experimental correlation is:

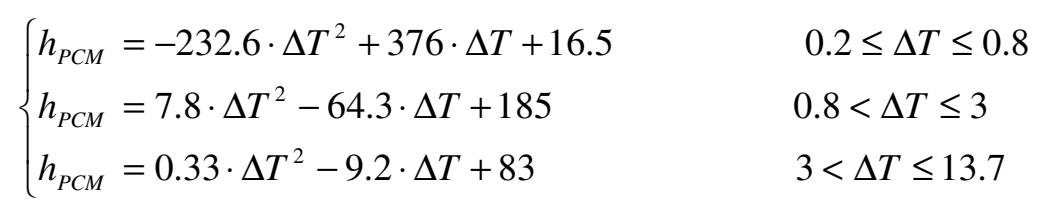

In the first region the heat transfer coefficient increases with $\Delta T$. The maximum value for the coefficient is achieved at the intersection point between first and second region. For higher values of temperature differences the heat transfer coefficient decreased to the half of the maximum value. Finally, in the third region the coefficient described a parabolic behaviour below values the half of the maximum.

For both cases, using $20 \mathrm{~mm}$ or $40 \mathrm{~mm}$ fins, the first and third region were approached with a polynomial regression. In the second region, when using $20 \mathrm{~mm}$ fins a lineal regression is good enough, while for $40 \mathrm{~mm}$ fins a polynomial regression is necessary.

Several experimental correlations representing Nusselt number as a function of different dimensionless numbers were determined. As showed before, there were three different regions in the heat transfer coefficient behaviour, so Nusselt number should be evaluated in each region individually.

First analysis consisted in plotting Nusselt number as a function of Rayleigh number for each geometry, as showed in Fig 7a and Fig 7b. The obtained correlations were, for $20 \mathrm{~mm}$ fins:

$$
\begin{array}{ll}
N u=-4 \cdot 10^{-22} \cdot R a^{2}+8 \cdot 10^{-10} \cdot R a+308 & 5 \cdot 10^{11} \leq R a \leq 1 \cdot 10^{12} \\
N u=3 \cdot 10^{-24} R a^{2}-4 \cdot 10^{-11} \cdot R a+127.6 & 1 \cdot 10^{12}<R a \leq 3.6 \cdot 10^{12} \\
N u=4 \cdot 10^{-25} \cdot R a^{2}-7 \cdot 10^{-12} \cdot R a+61.4 & 3.6 \cdot 10^{12} \leq R a \leq 6.5 \cdot 10^{12}
\end{array}
$$

For $40 \mathrm{~mm}$ fins:

$$
\begin{array}{lc}
N u=-2 \cdot 10^{-22} \cdot R a^{2}+2 \cdot 10^{-10} \cdot R a-4.7 & 7.1 \cdot 10^{10} \leq R a \leq 6 \cdot 10^{11} \\
N u=6 \cdot 10^{-24} \cdot R a^{2}-4 \cdot 10^{-11} \cdot R a+91.5 & 6 \cdot 10^{11}<R a<3 \cdot 10^{12} \\
N u=-4 \cdot 10^{-12} \cdot R a+35 & 3 \cdot 10^{12} \leq R a \leq 7.5 \cdot 10^{12}
\end{array}
$$


Nusselt number as a function of an effective Rayleigh number $\left(\mathrm{Ra}_{\mathrm{eff}}\right)$ was also studied, as showed in Fig. 8a and Fig. 8b. The experimental correlations were, for $20 \mathrm{~mm}$ fins:

$$
\begin{array}{lc}
N u=1 \cdot 10^{-11} \cdot R a_{\text {eff }}-98 & 8 \cdot 10^{12} \leq R a_{\text {eff }}<1.45 \cdot 10^{13} \\
N u=8 \cdot 10^{-27}\left(R a_{\text {eff }}\right)^{2}-2 \cdot 10^{-12} \cdot R a_{\text {eff }}+122 & 1.45 \cdot 10^{13} \leq R a_{\text {eff }} \leq 6 \cdot 10^{13}(5 \mathrm{a}) \\
N u=1 \cdot 10^{-27}\left(R a_{\text {eff }}\right)^{2}-5 \cdot 10^{-13} \cdot \mathrm{Ra}_{\text {eff }}-61.4 & 6 \cdot 10^{13} \leq R a_{\text {eff }} \leq 1 \cdot 10^{14}
\end{array}
$$

For $40 \mathrm{~mm}$ fins:

$$
\begin{array}{ll}
N u=-3 \cdot 10^{-24} \cdot\left(R a_{e f f}\right)^{2}+3 \cdot 10^{-11} \cdot R a_{\text {eff }}-4.7 & 5 \cdot 10^{11} \leq R a_{\text {eff }} \leq 5 \cdot 10^{12} \\
N u=1 \cdot 10^{-25} \cdot\left(R a_{\text {eff }}\right)^{2}-5 \cdot 10^{-12} \cdot R a_{\text {eff }}+93 & 5 \cdot 10^{12}<R a_{\text {eff }}<2 \cdot 10^{13} \\
N u=3 \cdot 10^{-28} \cdot\left(R a_{\text {eff }}\right)^{2}-5 \cdot 10^{-13} \cdot R a_{\text {eff }}+35 & 2 \cdot 10^{13} \leq R a_{\text {eff }} \leq 6 \cdot 10^{13}
\end{array}
$$

Both correlations showed a similar behaviour. In the first region Nusselt number increased with Rayleigh and effective Rayleigh numbers respectively. The maximum value for the Nusselt number was achieved at the intersection point between first and second region. For bigger values of Rayleigh and effective Rayleigh numbers the Nusselt number decreased to values lower than half of the maximum. Finally, in the third region the Nusselt number described a parabolic behaviour obtaining values lower than a third part of the maximum.

For both cases, using $20 \mathrm{~mm}$ or $40 \mathrm{~mm}$ fins, the obtained correlations were very similar. Also comparing Rayleigh and Effective Rayleigh the results were similar. A polynomial regression was used in most cases.

\section{Discussion}

The increase of the heat transfer rate was a result of the increase of the heat transfer area and the lower temperature difference necessary to achieve the same heat transfer coefficient for natural convection. 
The heat transfer coefficient was not increased by using vertical fins. When using small fins, a lower temperature difference was necessary to achieve the same heat transfer coefficient as with no fins. Therefore, the needed time to solidify the PCM decreased. The increase of the heat transfer area resulted in an increase of heat transfer rate.

When using big fins, the heat transfer coefficient was lower. The increase of the fins width may have interfered the natural convection. Nevertheless, the needed time to solidify the PCM was also reduced because of the increase of the heat transfer area.

The increase of the heat transfer rate obtained by using vertical fins could be very useful for applications of PCM modules inside water tanks. These PCM modules are used to store energy in a reduced volume. Using modules with vertical fins could solve the problem of slow heat transfer rate from the PCM to the water and increase the availability of the energy. The storage system would be more flexible to match the energy demand.

The behaviour of the system with vertical fins was well defined using both correlations, Rayleigh and effective Rayleigh. There were no significant differences in the quadratic mean difference or the complexity of the function describing the system, as showed in Table 1. The accuracy of the correlations was not affected by the fin width. Additional experimental work using fins with different width should be done in order to determine a unique correlation that represented all the studied cases. In this correlation, the modifying factor $\frac{W_{f i n}}{L_{P C M}}$ should be important.

To simplify the calculations, the authors recommend using the Nusselt over Rayleigh correlation. The accuracy was the same as when using Nusselt over effective Rayleigh correlation, but it was easier to determine the Rayleigh number.

In conclusion, the use of external fins in PCM modules reduced the time necessary for the heat transfer to the surrounding water. The temperature difference necessary to achieve a certain 
value of the heat transfer coefficient by natural convection was also reduced. The bigger the fins were, the faster was the heat transfer process, but the heat transfer coefficient was reduced. Finally, the authors recommend the use the Nusselt over Rayleigh correlation in order to simplify the calculations achieving the same precision in the results.

\section{Nomenclature}

A cond

$A_{\text {transfer }}$

$\mathrm{C}_{\mathrm{p}}$

$\mathrm{d}_{\mathrm{T}}$

$D_{P C M}$

$D_{t}$

g

Gr

$h_{P C M}$

$k_{P C M}$

$L_{P C M}$

$L_{t}$

$\mathrm{N}_{\text {fin }}$

$\mathrm{Nu}$

$\operatorname{Pr}$

q

$\mathrm{Ra}$

$\mathrm{Ra}_{\text {eff }}$

$r_{P C M}$ inner conduction heat transfer area .....

$\mathrm{m}^{2}$

convection heat transfer area from the modules to the water $m^{2}$ specific heat $\mathrm{kJ} /(\mathrm{kg} \cdot \mathrm{K})$ distance between thermocouples position in the experimentation work m PCM module diameter $\mathrm{m}$ tank diameter $\mathrm{m}$ gravity acceleration $\mathrm{m} / \mathrm{s}^{2}$

Grashof number, $=\frac{g \cdot \beta \cdot\left(T_{\text {surface }}-T_{\text {close }}\right) \cdot L_{P C M}{ }^{3}}{v^{2}}$

convection heat transfer coefficient $\mathrm{W} /\left(\mathrm{m}^{2} \cdot \mathrm{K}\right)$

PCM thermal conductivity $\mathrm{W} /(\mathrm{m} \cdot \mathrm{K})$

PCM module height $\mathrm{m}$ tank height $\mathrm{m}$ number of fins

Nusselt number, $=\frac{h \cdot L}{k}$

Prandtl number, $=\frac{\mu \cdot C_{p}}{k}$ heat transfer rate from the PCM to the water in the experimental work. W Rayleigh number, $=G r \cdot \operatorname{Pr}$

Effective Rayleigh number, $=G r \cdot \operatorname{Pr} \cdot \frac{W_{f i n}}{L_{P C M}}$

PCM module radius $\mathrm{m}$ 


\section{ACCEPTED MANUSCRIPT}

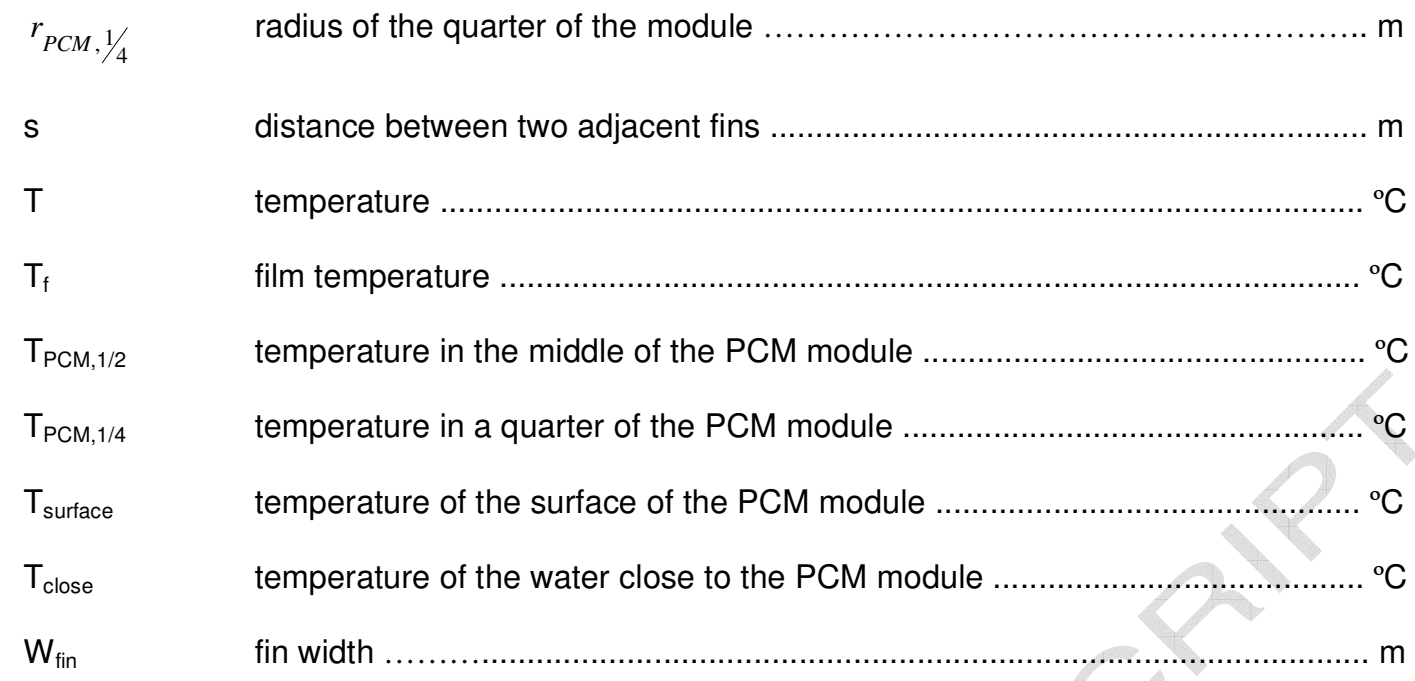

Greek symbols

$\beta \quad$ volumetric coefficient of thermal expansion ................................................ ${ }^{\circ} \mathrm{C}^{-1}$

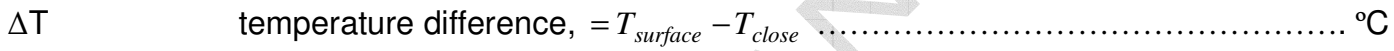

$\Phi \quad$ dimensionless number of $\mathrm{T},=\frac{T-T_{\text {close }}}{T_{\text {surface }}-T_{\text {close }}}$

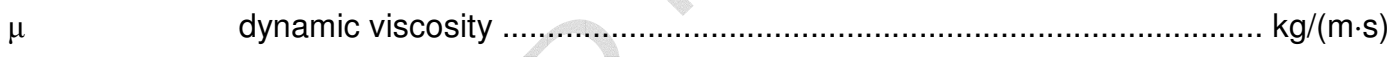

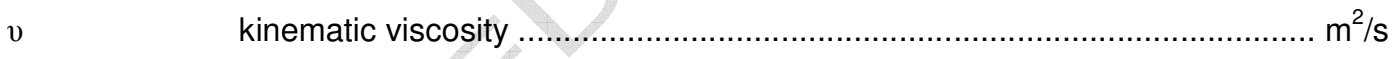

$\pi \quad$ Pi number

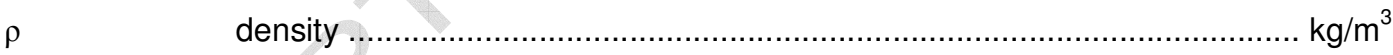

\section{References}

[1] L.F. Cabeza, M. Ibáñez, C. Solé, J. Roca, M. Nogués, Experimentation with a water tank including a PCM module, Solar Energy Materials and Solar Cells 90 (2006) 1273-1282.

[2] M. Ibáñez, L.F. Cabeza, C. Solé, J. Roca, M. Nogués, Modelization of a water tank including a PCM module, Applied Thermal Engineering 26 (2006) 1328-1333.

[3] K.A.R. Ismail, Modeling of Thermal Processes; Fusion and Solidification, ISBN 85-900609-3-

4, The State University of Campinas, Brasil, 1999 (in Portuguese).

[4] K.A.R. Ismail, Cold Storage Systems; Fundamentals and Modelling, ISBN 85-900-609-2-6, The State University of Campinas, Brasil, 1998 (in Portuguese). 
[5] K.A.R. Ismail, C.L.F. Alves, M.S. Modesto, Numerical and experimental study on the solidification of PCM around a vertical axially finned isothermal cylinder, Applied Thermal Engineering 21 (2001) 53-77

[6] H. Mehling, S. Hiebler, F. Ziegler, Latent heat storage using a PCM-graphite composite material: advantages and potential applications, Proceedings of the 4th Workshop of IEA ECES IA Annex 10, Bendiktbeuern (Germany), 1999.

[7] H. Mehling, S. Hiebler, F. Ziegler, Latent heat storage using a PCM-graphite composite material, Proceedings of Terrastock 2000 - 8th International Conference on Thermal Energy Storage, Stuttgart (Germany) (2000), pp. 375-380.

[8] L.F. Cabeza, H. Mehling, S. Hiebler, F. Ziegler, Heat transfer enhancement in water when used as PCM in thermal energy storage, Applied Thermal Engineering 22 (2002) 1141-1151. [9] X. Py, R. Olives, S. Mauran, Parafin/porous-graphite-matrix composite as a high and constant power thermal storage material, Int. J. Heat Mass Transfer 44 (2001) 2727-2737. [10] Esmail M.A. Mokheimer, Performance of annular fins with different profiles subject to variable heat transfer coefficient, Int. J. Heat and Mass Transfer 45 (2002) 3631-3642. [11] D.R. Harper, W.B. Brown, Mathematical Equations for Heat Conduction in the Fins of AirCooled Engines, National Advisory Committee for Aeronautics, Report no. 158, 1922.

[12] A. Ullmann, H. Kalman, Efficiency and optimized dimensions of annular fins of different cross-section shapes, Int. J. Heat Mass Transfer 32 (6) (1989) 1105-1110.

[13] R. Karaback, The effect of fin parameter on the radiation and free convection from a finned horizontal cylindrical heater, Energy Convers. Mgmt. 33 (11) (1992) 997-1005.

[14] A. Campo, L. Harrison, Prediction of safe tip temperature in uniform annular fins for the design of thermal exchange equipment via symbolic mathematics, Int. Commun. Heat Mass Transfer 21 (4) (1994) 531-538.

[15] P. Razelos, K. Imre, The optimum dimensions of circular fins with variable thermal parameters, Trans. ASME, J. Heat Transfer 102 (1980) 420-425.

[16] K. Laor, H. Kalman, Performance and optimum dimensions of different cooling fins with a temperature dependent heat transfer coefficient, Int. J. Heat Mass Transfer 39 (9) (1996) 19932003. 


\section{ACCEPTED MANUSCRIPT}

[17] S.M. Zubair, A.Z. Al-garni, J.S. Nizami, The optimal dimensions of circular fins with variable profile and temperature-dependent thermal conductivity, Int. J. Heat Mass Transfer 39 (16) (1996) 3431-3439.

[18] H.C. Unal, Determination of the temperature distribution in an extended surface with a nonuniform heat transfer coefficient, Int. J. Heat Mass Transfer 28 (12) (1985) 2270-2284.

[19] A.K. Sen, S. Trinh, An exact solution for the rate of heat transfer from rectangular fin governed by a power law-type temperature dependence, Trans. ASME, J. Heat Transfer 108 (1986) 457-459.

[20] A. Campo, R.E. Stuffle, Symbolic mathematics for calculation of thermal efficiencies and tip temperatures in annular fins of uniform thickness, Int. J. Heat Mass Transfer 40 (2) (1996) 490492.

[21] Lien-Tsaiyu, Cha'o Kuang Chen, Application of the Taylor transformation to the transient temperature response of an annular fin, Heat Transfer Eng. 20 (1) (1999) 78-87.

[22] J. R. Turnpenny, D. W. Etheridge, D. A. Reay, Novel ventilation cooling system for reducing air conditioning in buildings. Part I: testing and theoretical modelling, Applied Thermal Engineering 20 (2000) 1019-1037.

[23] E. Hahne, D. Zhu. Natural convection heat transfer on finned tubes in air, International Journal of Heat and Mass Transfer 37 (Supp.1) (1994) 59-63

[24] F. Farhadi, N. Davani, P. Ardalan. New correlation for natural convection of finned tube Atype air cooler, Applied Thermal Engineering 25 (2005) 3053-3066 
Table 1. Correlations for modules with vertical fins.

\begin{tabular}{|c|c|c|c|c|c|c|c|c|c|}
\hline \multirow{2}{*}{ Experiment } & \multirow{2}{*}{ Region } & \multirow{2}{*}{$\begin{array}{c}\text { Correlation } \\
(y \text { vs x })\end{array}$} & \multirow{2}{*}{$n^{(1)}$} & \multirow{2}{*}{ a } & \multirow{2}{*}{ b } & \multirow{2}{*}{ c } & \multirow{2}{*}{$r^{2(2)}$} & \multicolumn{2}{|c|}{ Valid range } \\
\hline & & & & & & & & Low $^{(3)}$ & High $^{(4)}$ \\
\hline \multirow{9}{*}{$20 \mathrm{~mm}$ fin } & \multirow{3}{*}{ First region } & $h_{P C M}$ vs $\Delta T$ & \multirow{3}{*}{14} & -490.6 & 1249 & 619 & 0.84 & $\geq 0.7$ & $\leq 1.3$ \\
\hline & & Nu vs Ra & & $-4 \cdot 10^{-22}$ & $8 \cdot 10^{-10}$ & 308 & 0.79 & $\geq 5 \cdot 10^{11}$ & $\leq 1 \cdot 10^{12}$ \\
\hline & & Nu vs $R a_{\text {eff }}$ & & & $1 \cdot 10^{-11}$ & -98 & 0.76 & $\geq 8 \cdot 10^{12}$ & $<1.45 \cdot 10^{13}$ \\
\hline & \multirow{3}{*}{ Second region } & $\mathrm{h}_{\mathrm{PCM}}$ vs $\Delta \mathrm{T}$ & \multirow{3}{*}{15} & & -35.7 & 226 & 0.98 & $>1.3$ & $\leq 3.7$ \\
\hline & & Nu vs Ra & & $3 \cdot 10^{-24}$ & $-4 \cdot 10^{-11}$ & 127.6 & 0.98 & $>1 \cdot 10^{12}$ & $\leq 3.6 \cdot 10^{12}$ \\
\hline & & Nu vs $R a_{\text {eff }}$ & & $8 \cdot 10^{-27}$ & $-2 \cdot 10^{-12}$ & 122 & 0.98 & $\geq 1.45 \cdot 10^{13}$ & $\leq 6 \cdot 10^{13}$ \\
\hline & \multirow{3}{*}{ Third region } & $h_{P C M}$ vs $\Delta T$ & \multirow{3}{*}{13} & 1.35 & -24 & 163.7 & 0.98 & $\geq 3.7$ & $\leq 9.2$ \\
\hline & & Nu vs $\mathrm{Ra}$ & & $4 \cdot 10^{-25}$ & $-7 \cdot 10^{-12}$ & 61.4 & 0.99 & $\geq 3.6 \cdot 10^{12}$ & $\leq 6,5 \cdot 10^{12}$ \\
\hline & & Nu vs $R a_{\text {eff }}$ & & $1 \cdot 10^{-27}$ & $-5 \cdot 10^{-13}$ & 61.4 & 0.99 & $\geq 6 \cdot 10^{13}$ & $\leq 1 \cdot 10^{14}$ \\
\hline \multirow{9}{*}{40 mm fin } & \multirow{3}{*}{ First region } & $h_{P C M}$ vs $\Delta T$ & \multirow{3}{*}{73} & -232.6 & 376 & 16.5 & 0.64 & $\geq 0.2$ & $\leq 0.8$ \\
\hline & & Nu vs Ra & & $-2 \cdot 10^{-22}$ & $2 \cdot 10^{-10}$ & -4.7 & 0.64 & $\geq 7.1 \cdot 10^{10}$ & $\leq 6 \cdot 10^{11}$ \\
\hline & & Nu vs $R a_{\text {eff }}$ & & $-3 \cdot 10^{-24}$ & $3 \cdot 10^{-11}$ & -4.7 & 0.64 & $\geq 5 \cdot 10^{11}$ & $\leq 5 \cdot 10^{12}$ \\
\hline & \multirow{3}{*}{ Second region } & $h_{P C M}$ vs $\Delta T$ & \multirow{3}{*}{54} & 7.8 & -64.3 & 185 & 0.88 & $>0.8$ & $\leq 3$ \\
\hline & & Nu vs Ra & & $6 \cdot 10^{-24}$ & $-4 \cdot 10^{-11}$ & 91.5 & 0.89 & $>6 \cdot 10^{11}$ & $<3 \cdot 10^{12}$ \\
\hline & & Nu vs $R a_{\text {eff }}$ & & $1 \cdot 10^{-25}$ & $-5 \cdot 10^{-12}$ & 93 & 0.88 & $>5 \cdot 10^{12}$ & $\leq 2 \cdot 10^{13}$ \\
\hline & \multirow{3}{*}{ Third region } & $h_{P C M}$ vs $\Delta T$ & & 0.33 & -9.2 & 83 & 0.83 & $>3$ & $\leq 13.7$ \\
\hline & & Nu vs Ra & 30 & 8 & $-4 \cdot 10^{-12}$ & 35 & 0.72 & $\geq 3 \cdot 10^{12}$ & $\leq 7.5 \cdot 10^{12}$ \\
\hline & & Nu vs $R a_{\text {eff }}$ & & $3 \cdot 10^{-28}$ & $-5 \cdot 10^{-13}$ & 35 & 0.73 & $>2 \cdot 10^{13}$ & $\leq 6 \cdot 10^{13}$ \\
\hline
\end{tabular}

$\mathrm{Y}=a \mathrm{x}^{2}+\mathrm{bx}+\mathrm{c}$

(1) $\mathrm{n} \rightarrow$ Number of experimental data

(2) $r^{2} \rightarrow$ Quadratic mean difference

(3) Low $\rightarrow$ Lower value of the rang of application

${ }^{(4)}$ High $\rightarrow$ Higher value of the rang of application 
FIGURE CAPTIONS

Fig. 1. Module with external vertical fins.

Fig. 2. Diagram of the experimental set-up.

Fig. 3. Instrumentation of the experiments.

Fig. 4a. Water and PCM temperature over time of experimental work using a PCM module without fins.

Fig. 4b. Water and PCM temperature over time of experimental work using a PCM module with vertical external fins of $20 \mathrm{~mm}$ length.

Fig. 4c. Water and PCM temperature over time of experimental work using a PCM module with vertical external fins of $40 \mathrm{~mm}$ length.

Fig. 5. Comparison of the heat transfer coefficient for natural convection for different PCM modules.

Fig.6a. Experimental correlation for natural convection coefficient for a PCM module with $20 \mathrm{~mm}$ fins.

Fig. 6b. Experimental correlation for natural convection coefficient for a PCM module with 40 $\mathrm{mm}$ fins.

Fig. 7a Experimental correlation of Nusselt number in function of Rayleigh number for a module with $20 \mathrm{~mm}$ fins.

Fig. 7b Experimental correlation of Nusselt number in function of Rayleigh number for a module with $40 \mathrm{~mm}$ fins.

Fig. 8a Experimental correlation of Nusselt number in function of Rayleigh effective number for a module with $20 \mathrm{~mm}$ fins.

Fig. $8 \mathrm{~b}$ Experimental correlation of Nusselt number in function of Rayleigh effective number for a module with $40 \mathrm{~mm}$ fins. 


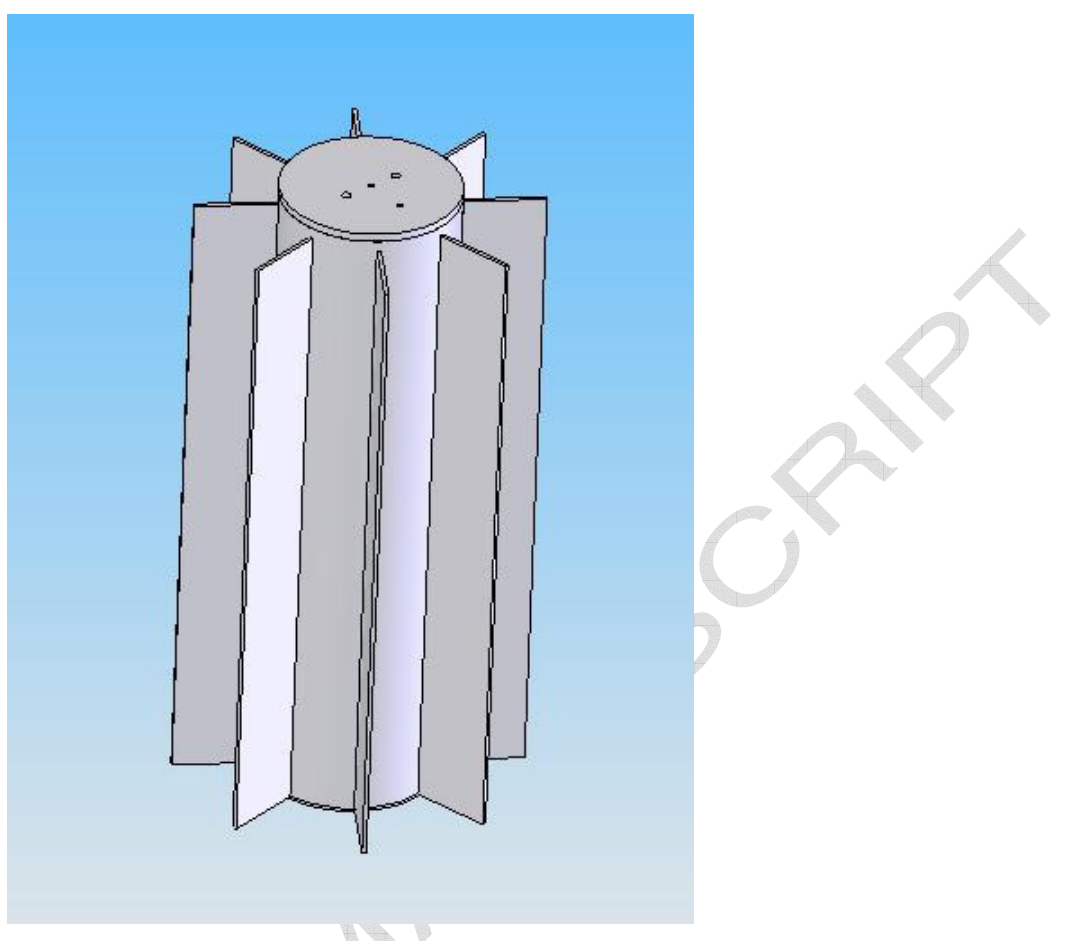

Fig. 1 


\section{ACCEPTED MANUSCRIPT}

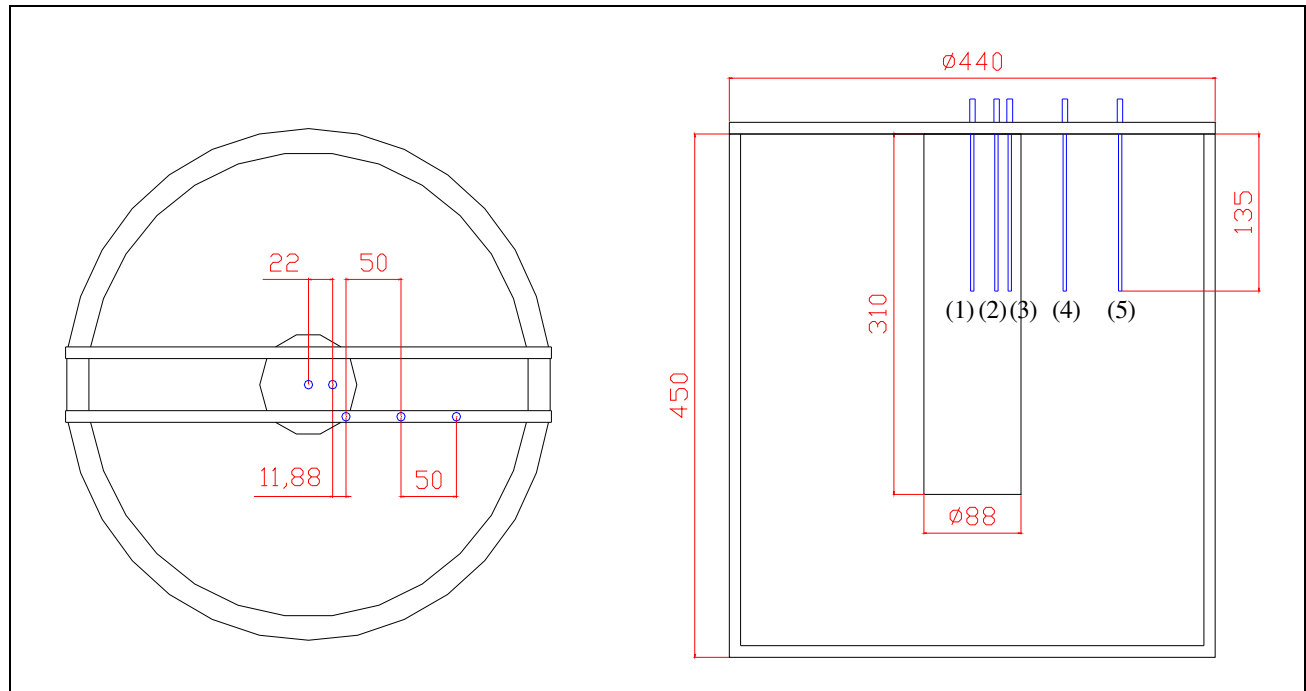

$\begin{array}{lllll}\text { (1) } T_{P C M, 1 / 2} & \text { (2) } T_{P C M, 1 / 4} & \text { (3) } T_{\text {surface }} & \text { (4) } T_{\text {close }} & \text { (5) } T_{\text {far }}\end{array}$

Fig. 2 


\section{ACCEPTED MANUSCRIPT}

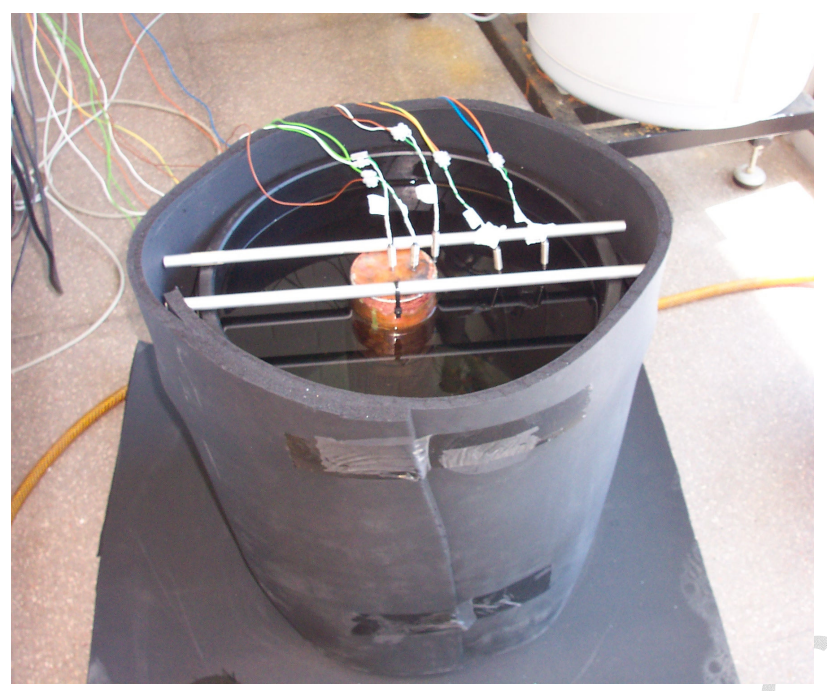

Fig. 3 


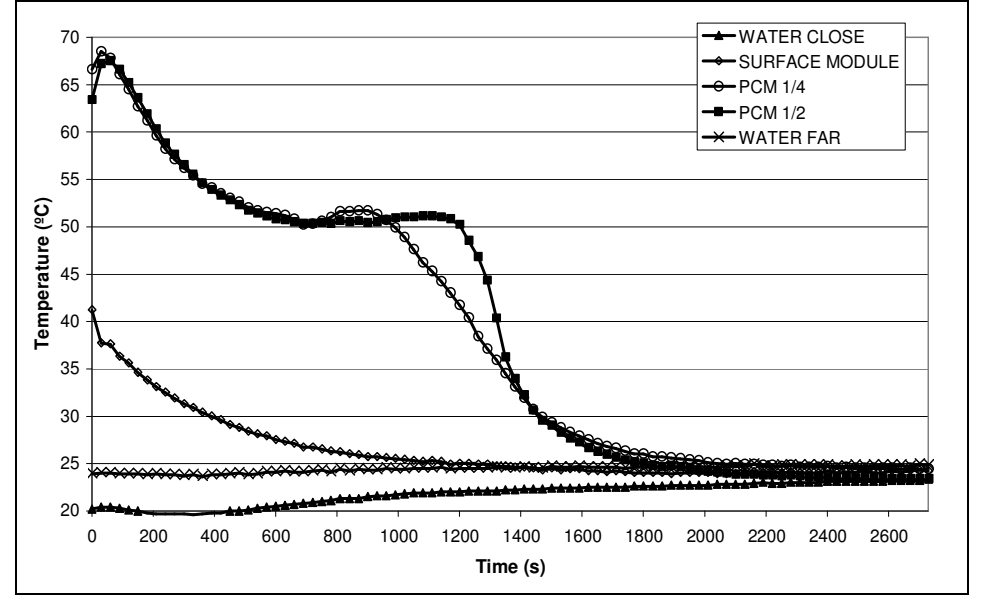

Fig. $4 a$

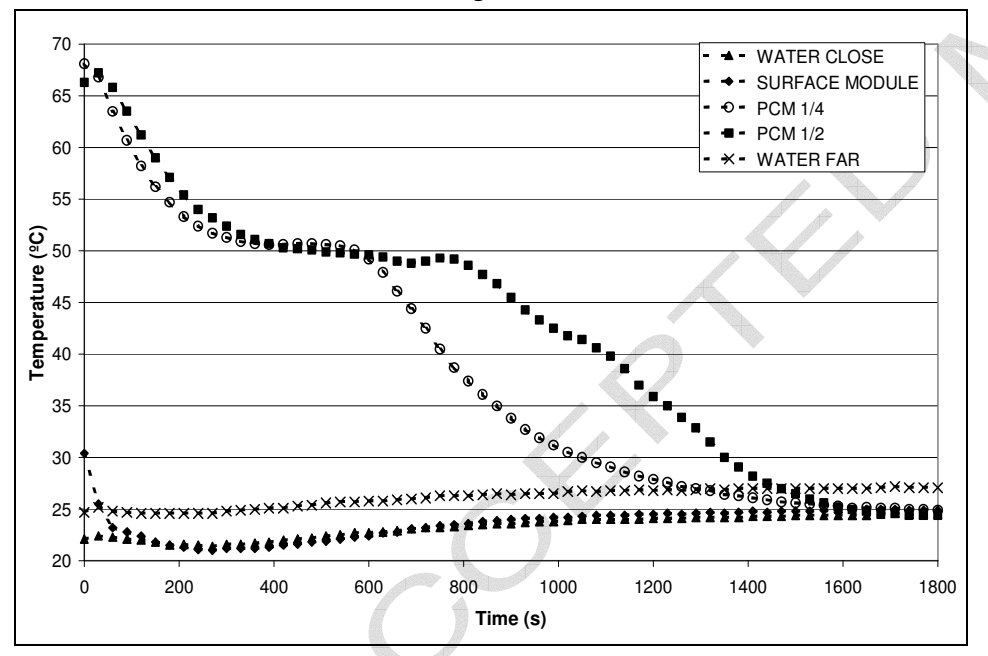

Fig. $4 b$

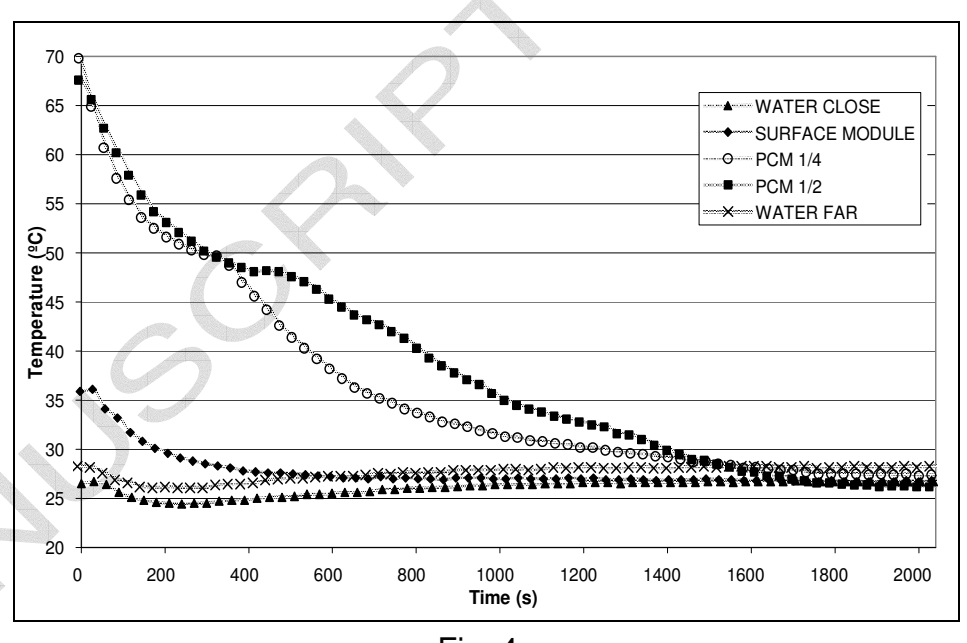

Fig. $4 \mathrm{c}$ 


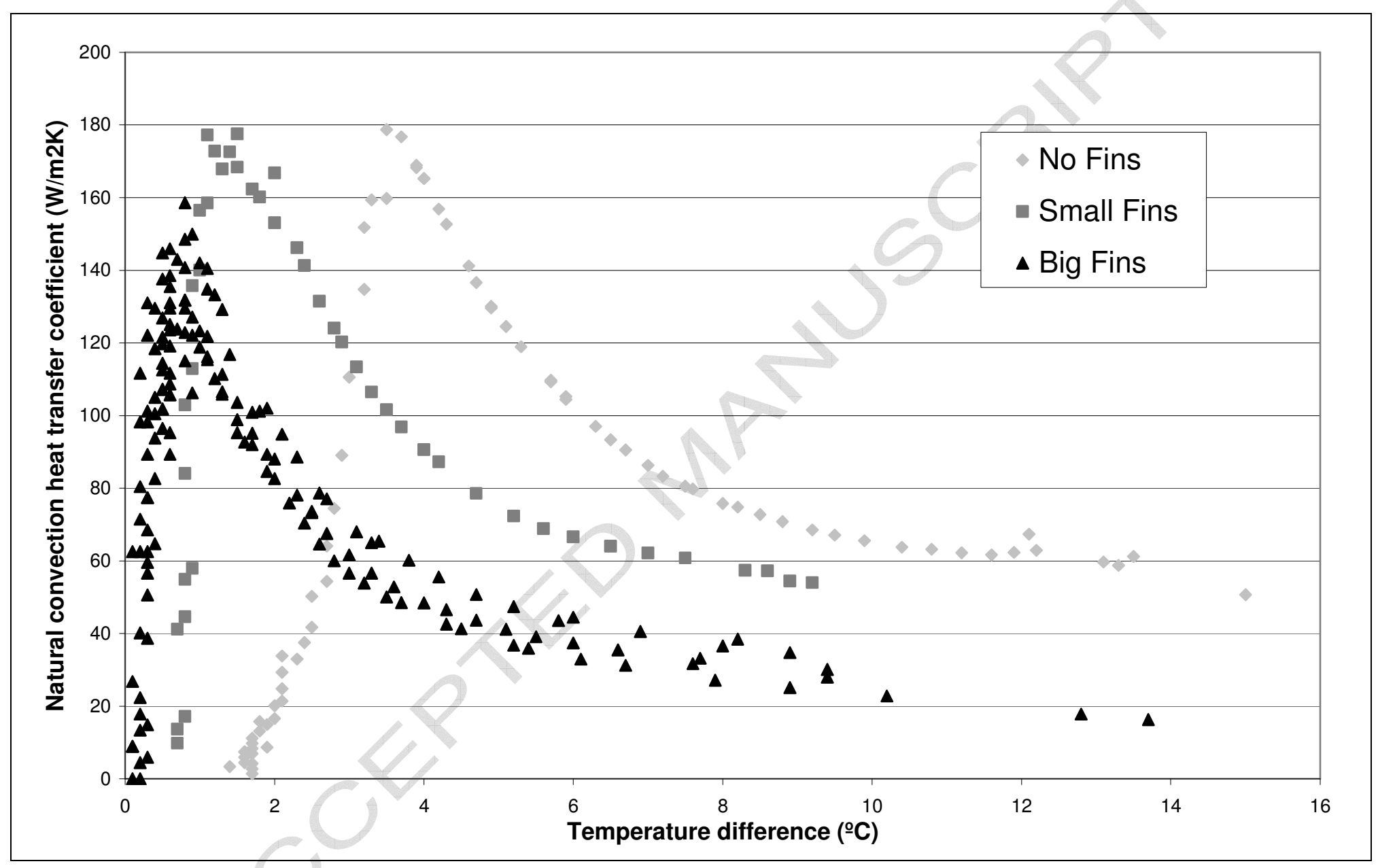

Fig. 5 


\section{ACCEPTED MANUSCRIPT}

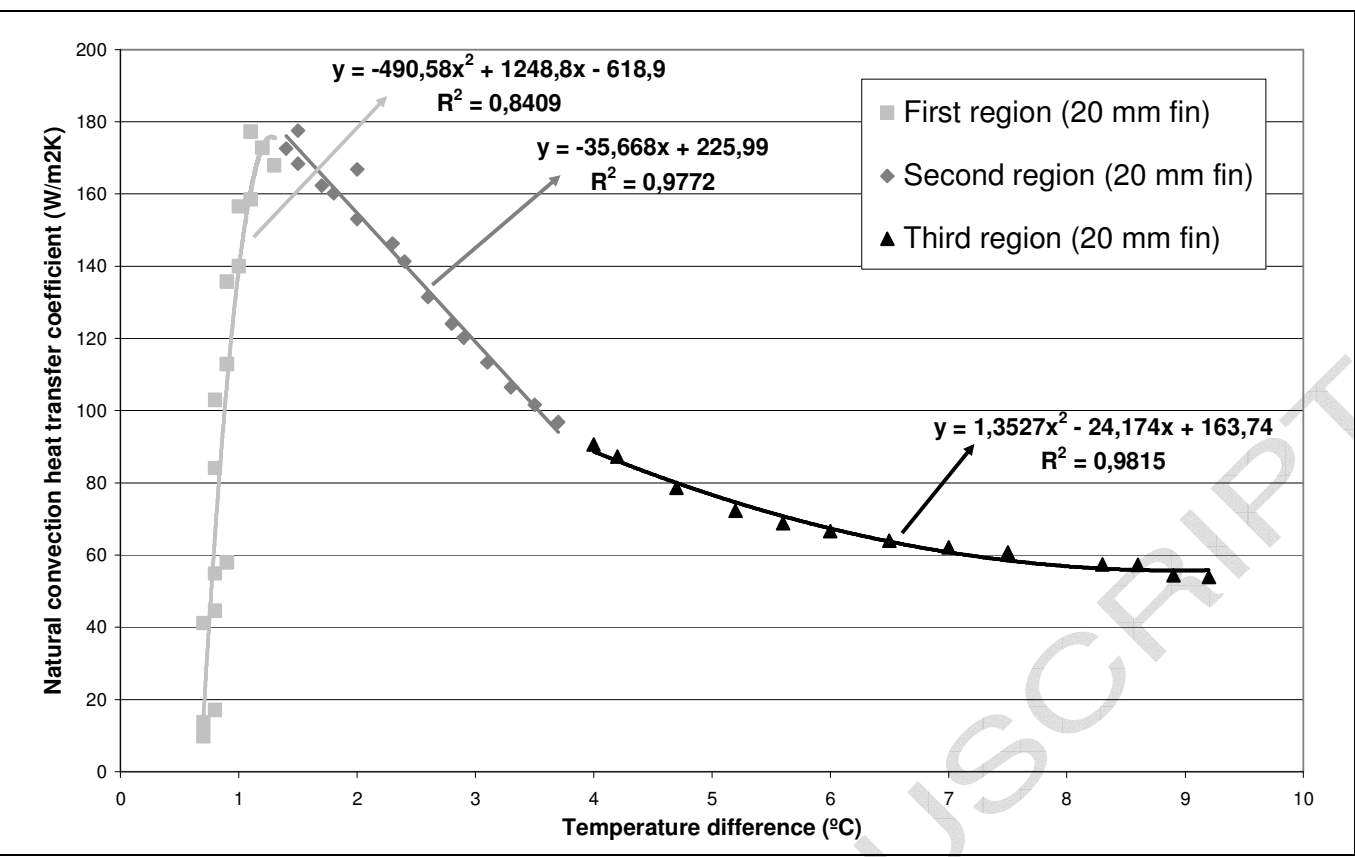

Fig. 6a

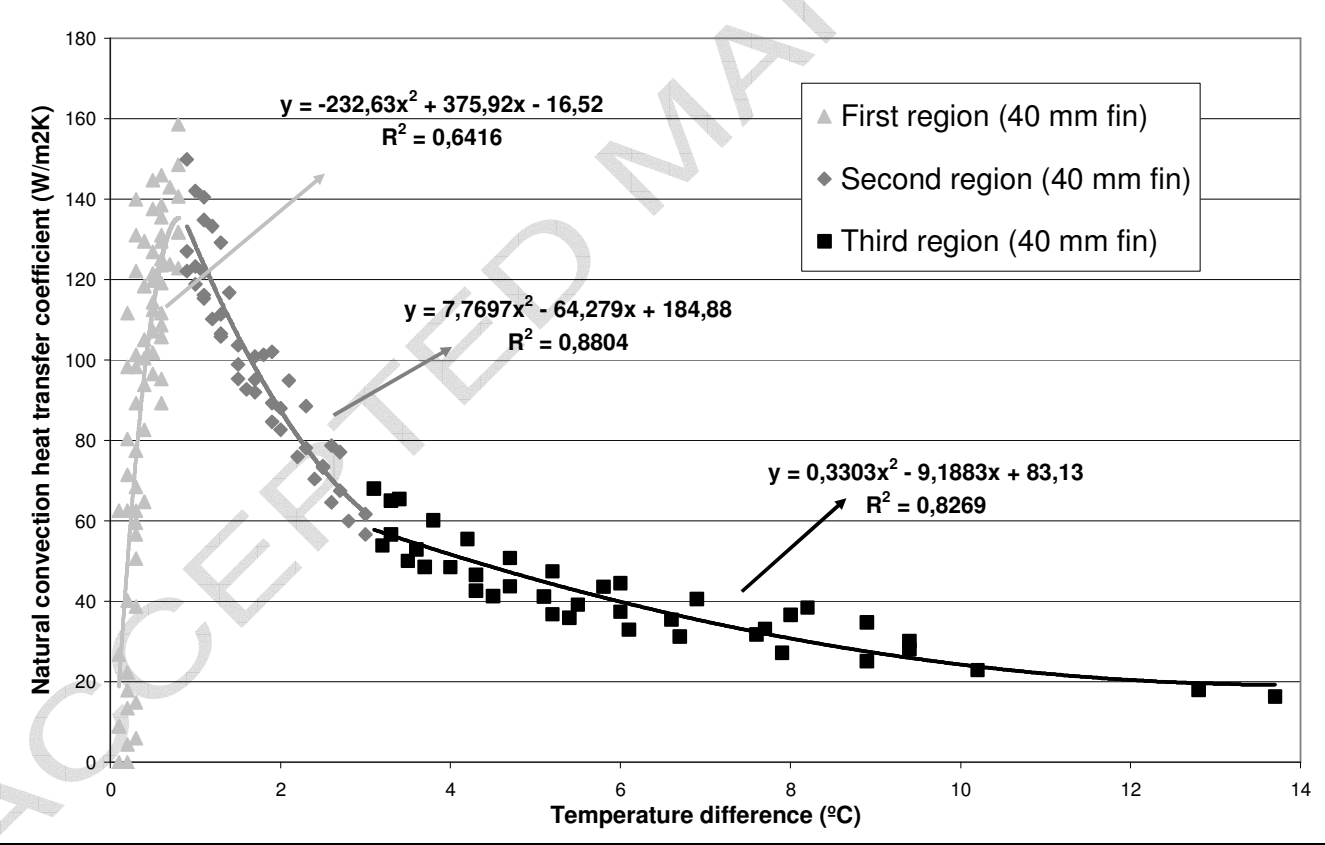

Fig. 6b 


\section{ACCEPTED MANUSCRIPT}

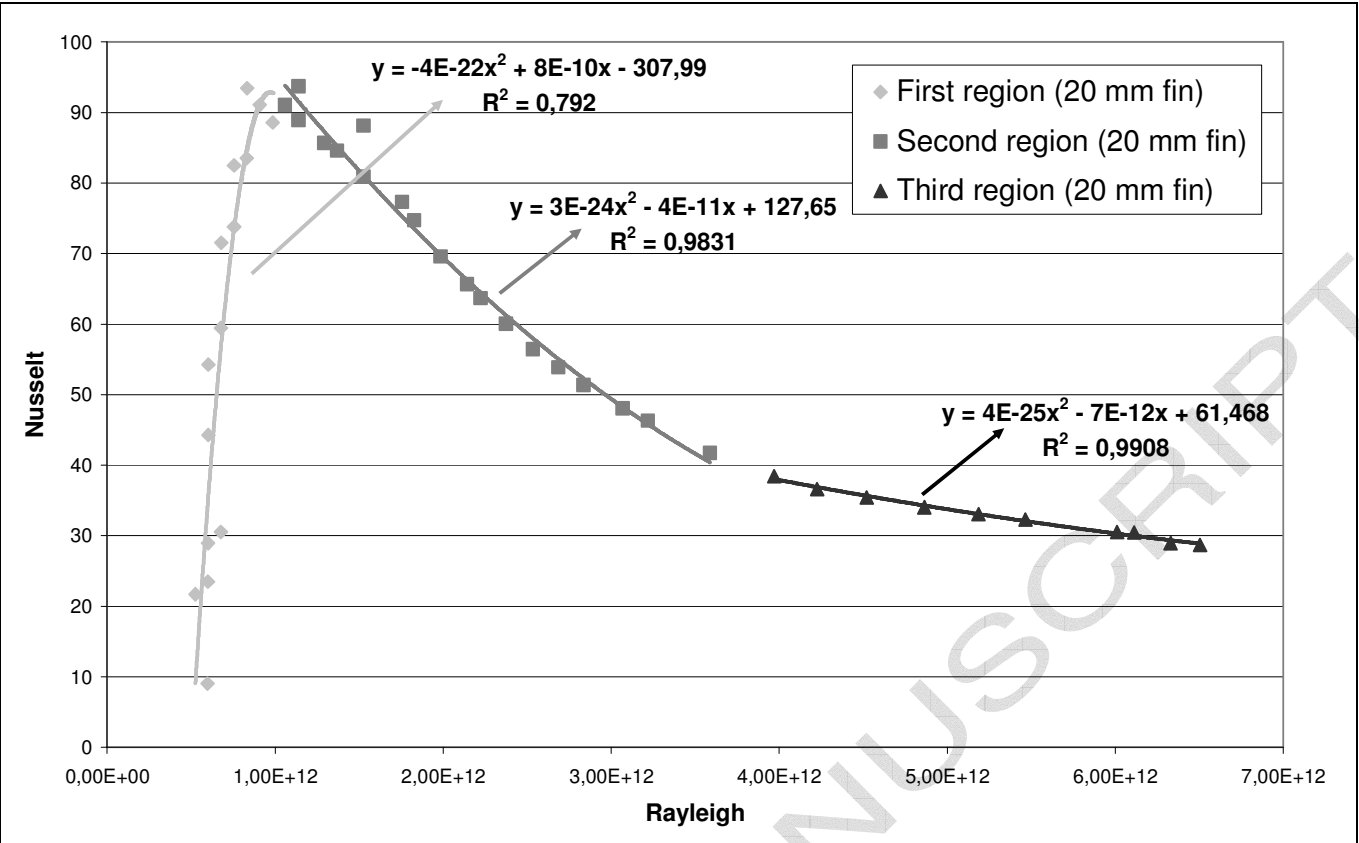

Fig. $7 a$

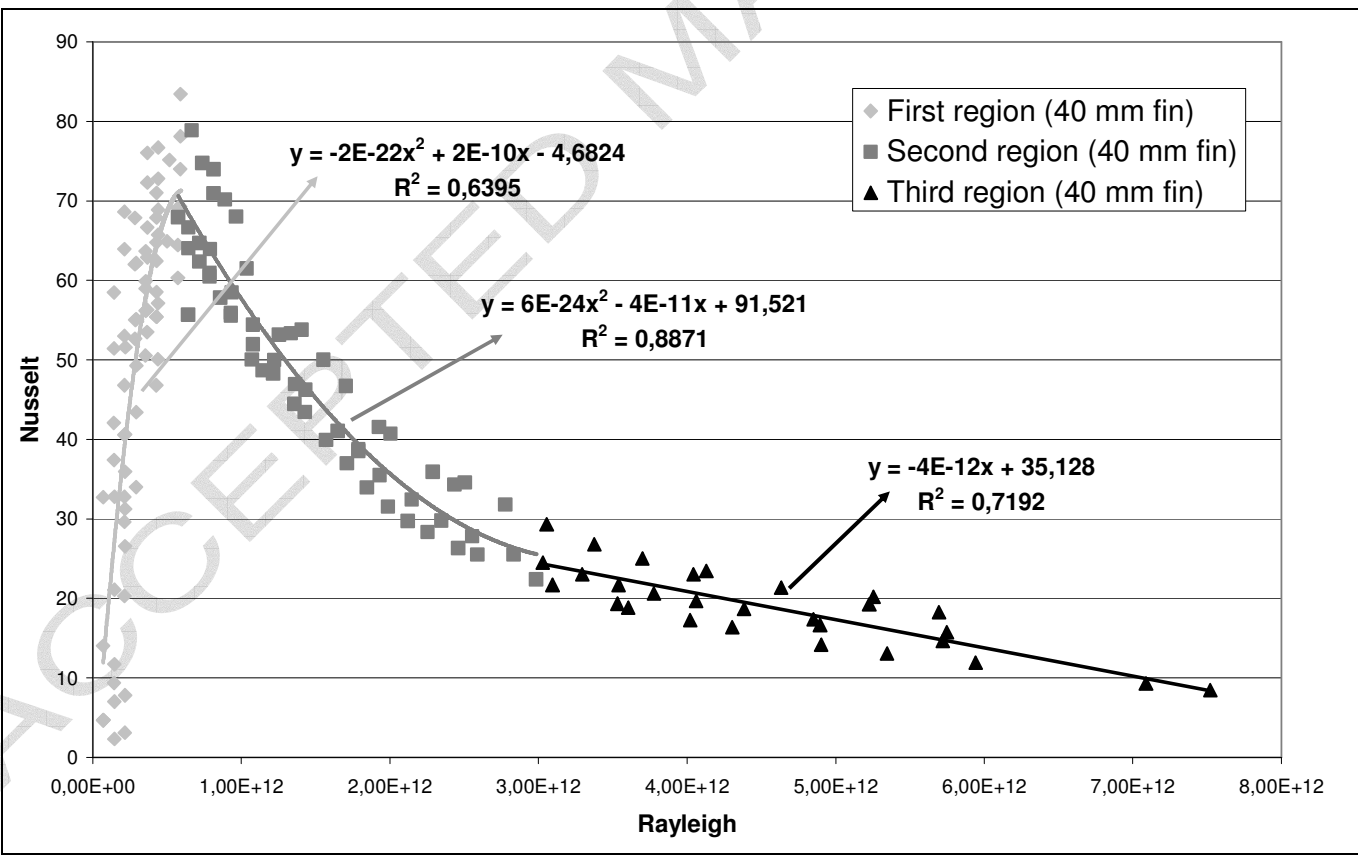

Fig. $7 \mathrm{~b}$ 


\section{ACCEPTED MANUSCRIPT}

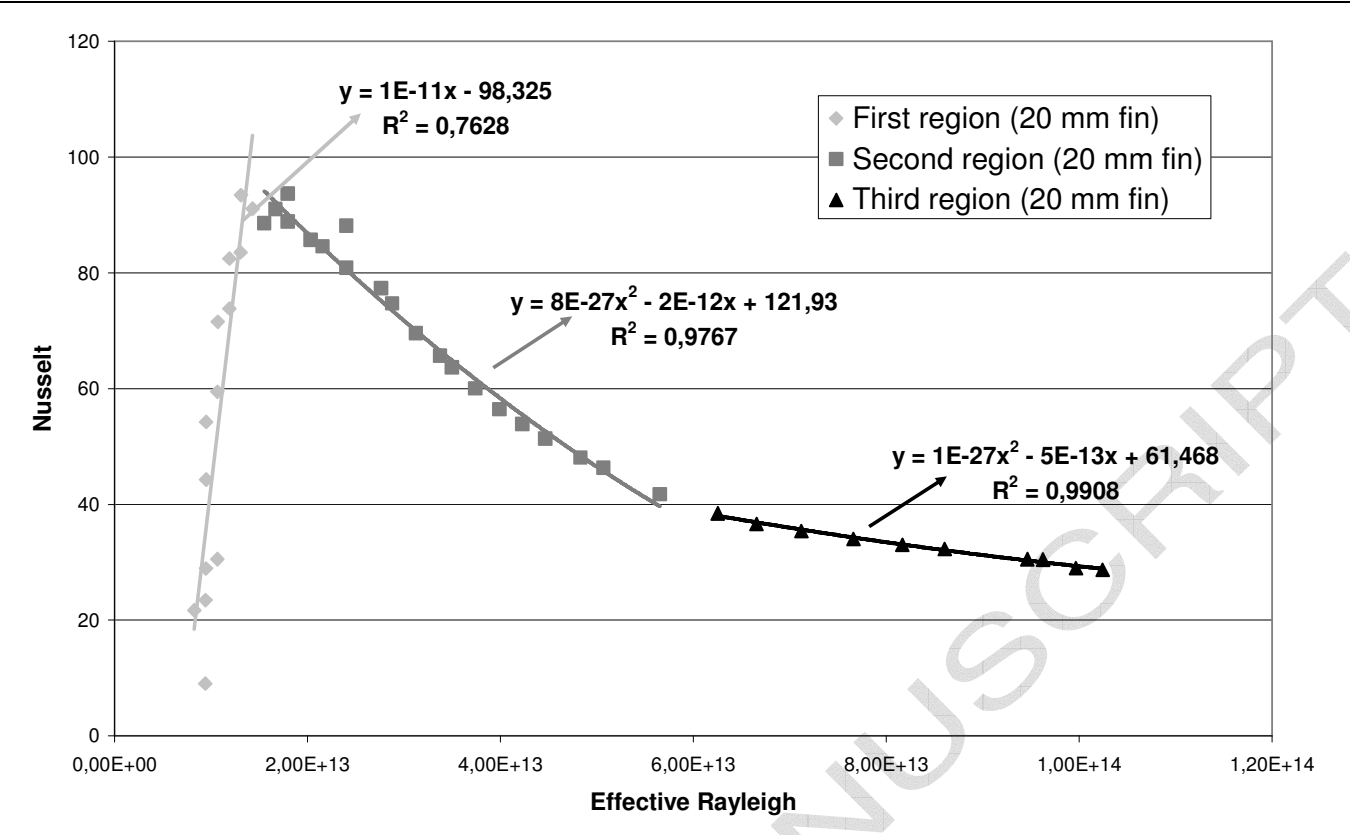

Fig. 8a

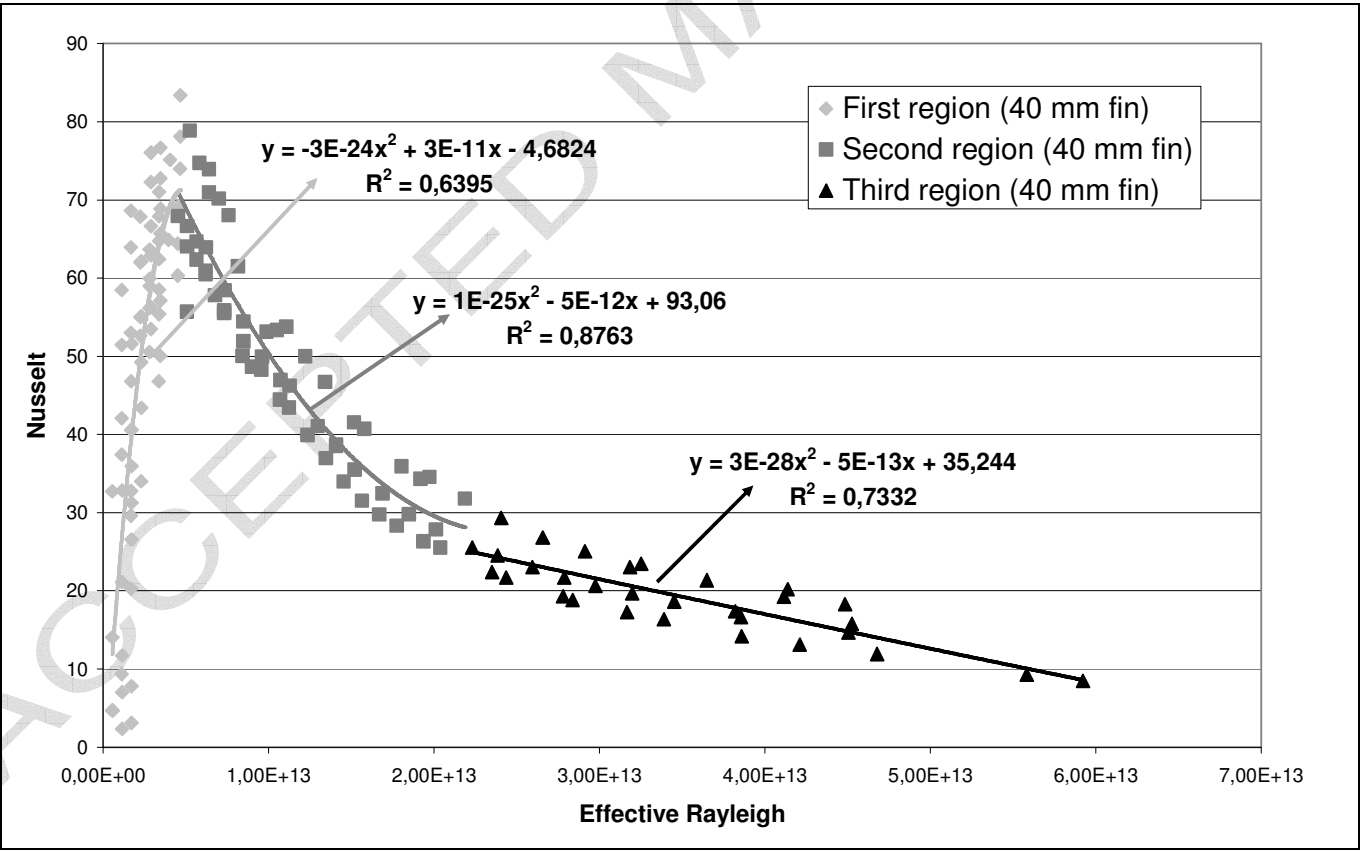

Fig. 8b 